\title{
The Influence of pH and Halide Ions on Cefuroxime Electrochemical Degradation
}

\author{
Bogdan Tutunaru, ${ }^{1, *}$ and Bogdan Oprea, ${ }^{2, *}$ \\ ${ }^{1}$ Department of Chemistry, Faculty of Sciences, University of Craiova, CUI: 4553380, Calea \\ București 107i, 200478 Craiova, Dolj, Romania; \\ ${ }^{2}$ Faculty of Medicine, University of Medicine and Pharmacy, Petru Rareș 2, 200349 Craiova, Dolj, \\ Romania; \\ *E-mail: tutunaruchim@yahoo.com; oprea.bogdan@yahoo.com
}

Received: 20 September 2021 / Accepted: 22 October 2021 / Published: 6 December 2021

\begin{abstract}
An optimal combination of $\mathrm{pH}$ and halide ion is considered an effective strategy for the removal of cefuroxime from wastewater accrued from hospitals and clinical laboratories. A conventional electrochemical system with two platinum electrodes was used, and the electrolyte solution had different compositions and different $\mathrm{pH}$ values. The study of redox processes at the electrode / electrolyte interface was performed on the basis of cyclic voltammetry $(\mathrm{CV})$ and constant current electrolysis supported by absorbance spectra obtained from UV-Vis spectrophotometry. The experimental results showed that the efficiency of antibiotic elimination can be increased to $100 \%$ in electrochemical systems by choosing the optimal parameters. Using the optimal conditions of the relevant factors, including the $\mathrm{pH}$ and nature of the anion, the degradation processes of cefuroxime in electrochemical systems are also compared by kinetic approach.
\end{abstract}

Keywords: cefuroxime; electrode processes; spectroelectrochemistry; electrodegradation

\section{$\underline{\text { FULL TEXT }}$}

(C) 2022 The Authors. Published by ESG (www.electrochemsci.org). This article is an open access article distributed under the terms and conditions of the Creative Commons Attribution license (http://creativecommons.org/licenses/by/4.0/). 